\title{
The relation between spirometric measurements and arterial blood gas analysis in patients with chronic airflow obstruction
}

\author{
ELAINEM. SHIBEL and KENNETH M. MOSER \\ The Pulmonary Divisions, University of California, San Diego Schools of Medicine, San Diego, \\ California, and Georgetown University, Washington, D.C.
}

Spirometric studies and arterial blood gas analyses were statistically evaluated in 75 patients with chronic airways obstruction to determine whether any spirometric parameters can predict arterial blood gas status. Radioactive lung scans, both ventilation (using ${ }^{133} \mathrm{Xe}$ gas) and perfusion (using ${ }^{131}$ I-MAA), were performed in selected patients.

In all 75 patients as one group, no spirometric parameter correlated with resting arterial blood gases. Comparing spirometric values with arterial blood studies during exercise, $5 \%$ carbon dioxide breathing and $100 \%$ oxygen breathing revealed no consistently predictive correlation coefficients.

Ventilation and perfusion lung scanning revealed that in patients whose ventilation/perfusion $(\dot{V} / Q)$ 'match' was good, arterial blood gases approached normal, while hypoxaemia and/or hypercapnia were present when $V / Q$ relationships were disturbed.

Spirometry measures static and dynamic lung volumes, reflecting the mechanical and structural status of the lung-bellows system. Arterial blood gas status is conditioned by severe factors, including $\mathbf{V} / Q$ relationship, and can be determined accurately only by measurement in each individual patient.

The need for pulmonary spirometric testing in the evaluation of patients with chronic airflow obstruction has gained increasing recognition (Baldwin, Cournand, and Richards, 1949; Sukumalchantra and Williams, 1965 ; Burrows and Earle, 1969). The value of arterial blood gas analysis (arterial oxygen tension, carbon dioxide tension, and $p \mathrm{H})$ in an assessment of such patients also has achieved wide acceptance (Baldwin et al., 1949 ; Smart, Naimi, and Capel, 1961 ; Boushy and Coates, 1964). Each procedure supplies information not provided by the other. Together, spirometry and blood gas analysis provide an instructive picture of the type and severity of respiratory dysfunction in a given individual.

Despite rather broad application of both techniques, however, rather limited attempts have been made to relate the two, that is to determine whether a given spirometric pattern is associated with a specific set of arterial blood gas values (Smart et al., 1961 ; Sinclair, 1955; Segall and Butterworth, 1966; Palmer and Diament, 1968). Varying conclusions have been reached. This study was performed to determine whether, in a large series of patients with airways obstruction, such a relationship could be found. In particular, an effort was made to learn if certain blood gas derangements could be accurately predicted from a known set of spirometric values. This is a ques. tion frequently posed in clinical practice; for example, 'With this maximum voluntary ventilation, can you guess the patient will be hypoxic at rest-and perhaps hypercapnic ?'

In addition, an attempt was made to obtain a more comprehensive picture of the factors influencing blood gas behaviour in the patient with chronic airflow obstruction through radioactive lung scintiphotography (Wagner, Sabiston, Iio, McAfee, Meyer, and Langan, 1964 ; Dore, Poe, Ellestad, and Taplin, 1968), both the ventilation (Newhouse, Wright, Ingham, Archer, Hughes, and Hopkins, 1968) and perfusion (Tisi, Landis, Miale, and Moser, 1968) scintillation studies being obtained.

MATERIALS AND METHODS

Data obtained from 75 patients studied in the pulmonary function laboratory at Georgetown University 
Hospital since 1964 were reviewed. All patients had chronic airways obstruction with highly abnormal expiratory flow rates (both one-second forced expiratory volume and maximum mid-expiratory flow rates) and residual volume/total lung capacity ratios greater than $40 \%$. All patients included in the study were ambulatory, and chronically rather than acutely ill.

All patients had complete static and dynamic spirometric evaluation and determination of arterial blood gases (oxygen tension, carbon dioxide tension, $p \mathrm{H}$ ) at rest. In addition, a majority of the patients had blood gas measurements during periods of exercise, $5 \%$ carbon dioxide and $100 \%$ oxygen breathing (group I, 43 patients). In 12 patients (group II) the exercise periods were omitted. In 20 patients (group III) one or all of the post-rest observations were not obtained (Table I).

\section{T A B L E I}

CLASSIFICATION OF 75 PATIENTS BY EXTENT OF

\begin{tabular}{c|c|c}
\hline Group & Arterial Study & $\begin{array}{c}\text { No. of } \\
\text { Patients }\end{array}$ \\
\hline I & $\begin{array}{c}\text { Complete spirometry and arterial blood } \\
\text { gas determinations at rest, during } \\
\text { exercise, during } 5 \% \mathrm{CO}_{2} \text { breathing } \\
\text { and } 100 \% \mathrm{O}_{2} \text { breathing } \\
\text { Complete spirometry and all arterial } \\
\text { blood gas studies except exercise } \\
\text { Complete spirometry and varying blood } \\
\text { gas studies as follows: } \\
(\text { a }) \text { resting sample, exercise and } \\
100 \% \text { O (6 patients) } \\
\text { (b) resting sample and } 100 \% \mathrm{O}_{2} \\
(10 \text { patients) } \\
\text { (c) resting sample only (4 patients) }\end{array}$ & 12 \\
\hline
\end{tabular}

Spirometric studies were performed with a Pulmotest spirometer. Functional residual capacity was determined by the helium dilution method. Arterial blood gases were analysed using an IL 133 blood gas analyser. Resting blood samples were obtained at least 10 minutes following insertion of an indwelling arterial needle. Exercise samples were drawn at the 9th to 10th minute of supine exercise (Fleisch ergostat) with a work-load deemed appropriate for the given patients (usually 25-75 watts). Breathing of the 5\% $\mathrm{CO}_{2}$ mixture and $100 \% \mathrm{O}_{2}$ were for 10 -minute periods as well.

All spirometric and arterial blood gas data were submitted to computer analysis. Correlation coefficients (R) were obtained between each pair of variables in each group as well as in the entire 75 patients as one group. The three groups were also analysed for significant differences in any given variable by Student's ' $t$ '.

Radionuclide lung studies (both ventilation and perfusion) were performed on selected patients using the Anger scintillation camera (Anger, 1963). A divided crystal was used so that counts could be recorded from each lung separately. For perfusion scans, a dose of $400 \mu \mathrm{Ci}$ of radioiodinated macroaggregated albumin (131I-MAA) was injected intravenously, half in the prone and half in the supine position (Moser and Miale, 1968). Scans were obtained in the postero-anterior (PA), antero-posterior (AP) and both lateral views.

Ventilation scans (Shibel, Landis, and Moser, 1969) were done using gaseous xenon-133 (133 Xe), 10 to $20 \mathrm{mCi}$ in approximately 5 litres of $100 \% \mathrm{O}_{3}$. The ${ }^{133} \mathrm{Xe}-\mathrm{O}_{2}$ mixture was placed in the bell of a Collins spirometer. A fan ensured continuous mixing of the gases in the closed system, and counts were continuously monitored with a counter on the inspiratory line. The patient was seated with his back to the camera, noseclip and mouthpiece applied, breathing room air. At the end of a normal expiration, the valve was opened to the spirometer, and the patient was instructed to take a full inspiration to total lung capacity and hold his breath for 30 seconds. Two 15-second photoscans and digital data were obtained during this time. Following this, the patient breathed in and out normally in the closed system, until a stable count rate was achieved on the inspiratory line, at which point equilibrium scans and digital data were obtained. The patient was then disconnected from the system and the ${ }^{133} \mathrm{Xe}-\mathrm{O}_{2}$ mixture was allowed to wash out, while photoscans and digital data were again obtained at 15-second intervals. Ventilation scans were performed only in the PA position.

\section{RESULTS}

SPIROMETRIC AND ARTERIAL BLOOD GAS DATA Mean values for the variables in each group are listed in Table II. The ' $t$ ' test performed on each variable revealed that there was no statistically significant difference between the three groups. However, scrutiny of the data reveals that group II consists of patients with slightly more severe

T A B L E I I

AVERAGE VALUES FOR ALUDATA

\begin{tabular}{|c|c|c|c|}
\hline & $\begin{array}{c}\text { Group I } \\
\text { (43 patients) }\end{array}$ & $\begin{array}{c}\text { Group II } \\
\text { (12 patients) }\end{array}$ & $\underset{\text { (20 patients) }}{\text { Group III }}$ \\
\hline $\begin{array}{l}\text { Age (yr.) } \\
\text { BSA (m.2) } \\
\text { VC (litres) } \\
\text { RV/TLC ( \%) } \\
\text { MVV (\% pred.) } \\
\text { FEV }(\%)\end{array}$ & $\begin{array}{l}56 \cdot 3 \pm 9 \cdot 7 \\
1 \cdot 73 \pm 0 \cdot 2 \\
2 \cdot 58 \pm 0.82 \\
51 \cdot 1 \pm 8 \cdot 6 \\
44 \cdot 0 \pm 18 \cdot 3 \\
44 \cdot 6 \pm 10.0\end{array}$ & $\begin{array}{l}63 \cdot 3 \pm 8 \cdot 4 \\
1 \cdot 72 \pm 0 \cdot 2 \\
1 \cdot 96 \pm 0 \cdot 4 \\
58 \cdot 3 \pm 7 \cdot 3 \\
27 \cdot 0 \pm 9 \cdot 1 \\
33 \cdot 9 \pm 7 \cdot 7\end{array}$ & $\begin{array}{l}57 \cdot 6 \pm 9.7 \\
1 \cdot 79 \pm 0.2 \\
1 \cdot 89 \pm 0.7 \\
55 \cdot 6 \pm 9 \cdot 6 \\
36.0 \pm 16.7 \\
49 \cdot 4 \pm 13.4\end{array}$ \\
\hline $\begin{array}{l}\text { (litres/sec.) } \\
\text { Resting } \mathrm{Po}_{2} \\
\text { Resting } \mathrm{pH}^{-} \\
\text {Resting } \mathrm{PCO}_{2} \\
\text { Exercise } \mathrm{Po}_{2}\end{array}$ & $\begin{array}{l}0.46 \pm 0.13 \\
73 \cdot 3 \pm 8 \cdot 8 \\
7 \cdot 45 \pm 0.03 \\
37 \cdot 8 \pm 5 \cdot 0 \\
75 \cdot 2 \pm 12 \cdot 2\end{array}$ & $\begin{array}{c}0.27 \pm 0.16 \\
67 \pm 9.8 \\
7.47 \pm 0.03 \\
38.8 \pm 6.0 \\
-\end{array}$ & $\begin{array}{c}0.43 \pm 0.34 \\
61 \pm 8 \cdot 6 \\
7.44 \pm 0.03 \\
46 \cdot 0 \pm 5 \cdot 8 \\
59.0 \pm 13.6\end{array}$ \\
\hline Exercise $p H$ & $7.41 \pm 0.04$ & - & $7.41 \pm 0.02$ \\
\hline Exercise $\mathrm{PCO}_{2}$ & $40 \cdot 5 \pm 5 \cdot 6$ & - & $\begin{array}{c}48 \cdot 3 \pm 8 \cdot 2 \\
(6 \text { patients) }\end{array}$ \\
\hline $\begin{array}{lll}5 \% & \mathrm{CO}_{2} & \mathrm{PO}_{2} \\
5 \% & \mathrm{CO}_{2} & \mathrm{PCO}_{2} \\
100 \% & \mathrm{O}_{2} & \mathrm{PCO}_{2}\end{array}$ & $\begin{array}{l}102 \pm 11 \cdot 6 \\
46 \cdot 3 \pm 5 \cdot 9 \\
40 \cdot 6 \pm 6 \cdot 7\end{array}$ & $\begin{array}{l}85 \cdot 8 \pm 10 \cdot 0 \\
50 \cdot 8 \pm 7 \cdot 3 \\
45 \cdot 4 \pm 8 \cdot 0\end{array}$ & $\begin{array}{c}\overline{-} \\
50 \cdot 6 \pm 8.5 \\
(16 \text { patients) }\end{array}$ \\
\hline
\end{tabular}

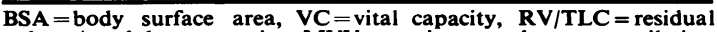
volume/total lung capacity, MVV=maximum voluntary ventilation $\left(\%\right.$ of predicted), $F E V_{1}=$ forced expiratory volume, 1 second $(\%$ predicted), MMFR=maximum mid-expiratory flow rate, $\mathrm{Po}_{2}=$ oxygen tension, $\mathrm{PCO}_{\mathbf{x}}=$ carbon dioxide tension. 
expiratory obstruction (lower FEV 1 and MMFR) than do groups I and III, while group III patients had a greater degree of resting hypoxaemia and hypercapnia than did groups I and II. In addition, mean $\mathrm{Po}_{2}$ during exercise fell in the six group III patients and rose slightly in group I patients.

Within each group, correlation coefficients (R) determined between each variable revealed that among spirometric data (Table III), measurements

T A B L E I I I

CORRELATION COEFFICIENTS FOR SPIROMETRIC DATA

\begin{tabular}{ll|c|c|c}
\hline & & Group I & Group II & Group III \\
\hline MMFR v. FEV & $\ldots$ & $+\mathbf{0 . 7 7}$ & +0.48 & $+\mathbf{0 . 8 1}$ \\
\% MVV v. MMRR & $\ldots$ & +0.74 & +0.73 & $+\mathbf{0 . 5 5}$ \\
$\%$ MVV v. FEV & $\ldots$ & +0.73 & +0.48 & +0.70 \\
\hline
\end{tabular}

of expiratory flow rate (MMFR and $\mathrm{FEV}_{1}$ ) correlated well with each other, as might be expected. In addition, per cent MVV correlated with flow rates to a statistically significant degree. Similar correlations could be found among many of the arterial blood gas parameters. For example, positive correlation was present between resting $\mathrm{PCO}_{\text {, }}$ and the $\mathrm{PCO}_{2}$ during $100 \% \mathrm{O}_{2}$ breathing in groups I and II $(\mathbf{R}=+0.74$ and +0.75 respectively).

Correlation coefficients between spirometric and arterial blood gas data are listed in Table IV. No correlation coefficient greater than 0.5 was found consistently in all groups. Resting $\mathrm{Po}_{2}$, for example, when compared to spirometric data, revealed Rs ranging from +0.13 to -0.33 in group I patients. In group II, values of $R$ ranged from +0.33 to -0.31 , and in group III from +0.28 to -0.23 .

In group II patients, when vital capacity was compared with resting $\mathrm{PCO}_{2}, \mathbf{R}$ was -0.55 . In groups I and III, comparison of the same para- meters resulted in $R$ values of -0.17 and -0.44 respectively.

No correlation coefficient of 0.5 or greater was found between spirometric and arterial blood gas data in group I. In group II, a correlation coefficient of -0.55 was present between per cent MVV and $\mathrm{PCO}_{2}$ after $100 \% \mathrm{O}_{2}$. This was statistically significant at $P<0.05$. An $R$ value of +0.63 between $\mathrm{FEV}_{1}$ and $\mathrm{PCO}_{2}$ after $5 \% \mathrm{CO}_{2}$ breathing was also significant at the $\mathrm{P}<0.05$ level.

In group III patients, negative correlation was present between vital capacity and $\mathrm{PcO}_{2}$ after $100 \% \mathrm{O}_{2}$ breathing $(\mathrm{R}=-0.62, \mathrm{P}<0.02)$, per cent maximum voluntary ventilation and $\mathrm{PCO}_{2}$ on exercise $(\mathbf{R}=-0.85, \mathbf{P}<0.05)$, per cent $\mathrm{MVV}$ and $\mathrm{PcO}_{2}$ on $100 \% \quad \mathrm{O}_{2}$ breathing $(\mathrm{R}=-0.61, \mathrm{P}<0.02)$ and maximum mid-expiratory flow rate and $\mathrm{PCO}_{2}$ on exercise $(\mathbf{R}=-0.92, \mathbf{P}<0.01)$. Other apparently high correlation coefficients were not significant in the numbers of patients included.

In all 75 patients as one group, spirometric data were compared with resting arterial blood gases. Correlation coefficients are listed in Table V. Values of $\mathbf{R}$ varied from $+0 \cdot 26$ to $-0 \cdot 31$.

VENTILATION AND PERFUSION SCANS The ${ }^{131}$ I perfusion scans and ${ }^{133} \mathrm{Xe}$ inhalation scans revealed varying patterns of abnormality. Figure 1 shows PA inhalation and perfusion lung scans in a patient with mild emphysema. A few patchy defects are seen on the perfusion scan, but, in general, the visual match between ventilation and perfusion is good. Arterial blood gases in this patient were nearly normal. In Fig. 2 are photoscans of a patient who has severe emphysema, with marked impairment of spirometric data. On both inhalation and perfusion scans large defects are seen. However, in both they are limited to the upper lobes. Again, nearly normal arterial blood

T A B L E I V

SPIROMETRIC-ARTERIAL BLOOD GAS CORR ELATIONS IN THREE GROUPS OF PATIENTS ${ }^{1}$

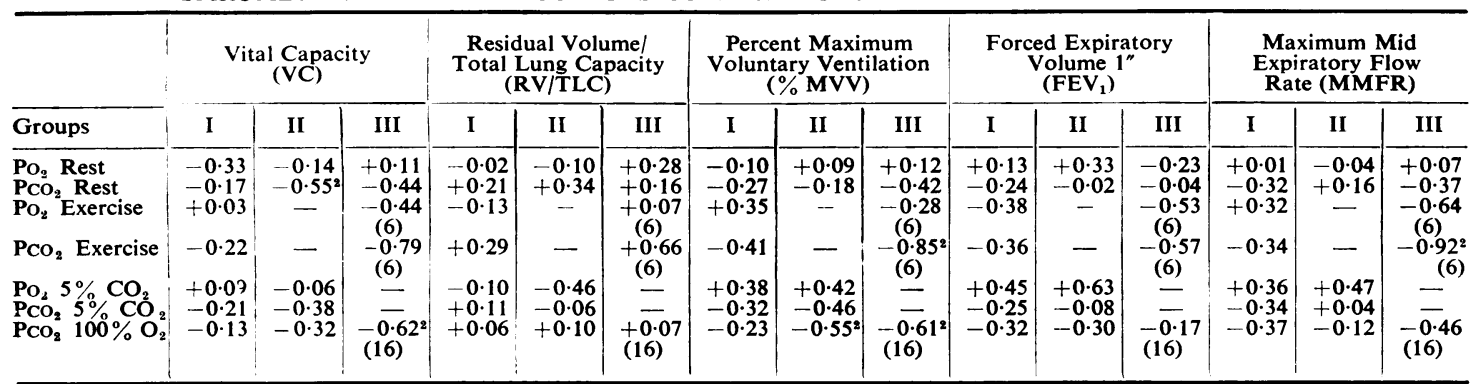

1 Group I, $N=43$; Group II, $N=12$; Group III, $N=20$. Numbers in parentheses indicate number of patients when these differ from total number in the group.

2 Correlation coefficient significant at $\mathbf{P}<0.05$. 
T A B L E V

SPIROMETRIC-ARTERIAL BLOOD GAS CORRELATIONS IN 75 PATIENTS

\begin{tabular}{|c|c|c|c|c|c|}
\hline & $\begin{array}{c}\text { Vital } \\
\text { Capacity } \\
\text { (VC) }\end{array}$ & $\begin{array}{c}\text { Residual } \\
\text { Volume/ } \\
\text { Total } \\
\text { Lung } \\
\text { Capacity } \\
\text { (RV/TLC) }\end{array}$ & $\begin{array}{c}\text { Percent } \\
\text { Maximum } \\
\text { Voluntary } \\
\text { Ventila- } \\
\text { tion } \\
(\% \text { MVV) }\end{array}$ & $\begin{array}{c}\text { Forced } \\
\text { Expiratory } \\
\text { Volume 1" } \\
\left(\mathrm{FEV}_{1}\right)\end{array}$ & $\begin{array}{c}\text { Maximum } \\
\text { Mid } \\
\text { Expiratory } \\
\text { Flow } \\
\text { Rate } \\
\text { (MMFR) }\end{array}$ \\
\hline $\begin{array}{l}\mathrm{PO}_{2} \text { Rest } \\
\mathrm{PCO}_{2} \text { Rest }\end{array}$ & $\begin{array}{l}+0.05 \\
-0.04\end{array}$ & $\begin{array}{r}-0.08 \\
+0.26\end{array}$ & $\begin{array}{l}+0.21 \\
-0.31\end{array}$ & $\begin{array}{r}-0.03 \\
+0.03\end{array}$ & $\begin{array}{l}+0.06 \\
-0.24\end{array}$ \\
\hline
\end{tabular}
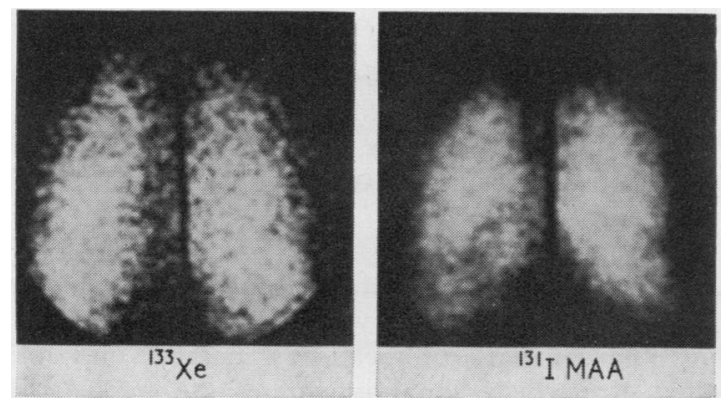

FIG. 1. ${ }^{133} \mathrm{Xe}$ ventilation scan and ${ }^{131}$ I-MAA perfusion scan in a patient with mild chronic airways obstruction. Both scans are in the antero-posterior projection. Mild, patchy defects in ventilation and perfusion are present but are comparable in extent and location. Arterial blood gases were normal.
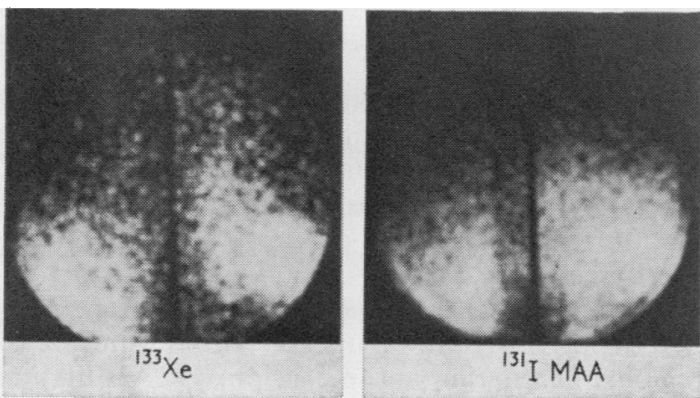

FIG. 2. Ventilation and perfusion scans (postero-anterior projection) in a patient with severe chronic airways obstruction. Severe abnormalities of ventilation and perfusion are present in both upper lobes. Arterial blood gases were essentially normal.

gases were present. Figure 3 reveals scans in a patient whose spirometric abnormalities were similar to those of the preceding patient. It can be seen that striking abnormalities of perfusion are present in both lower lobes, while ventilation is less impaired, suggesting that most of the blood
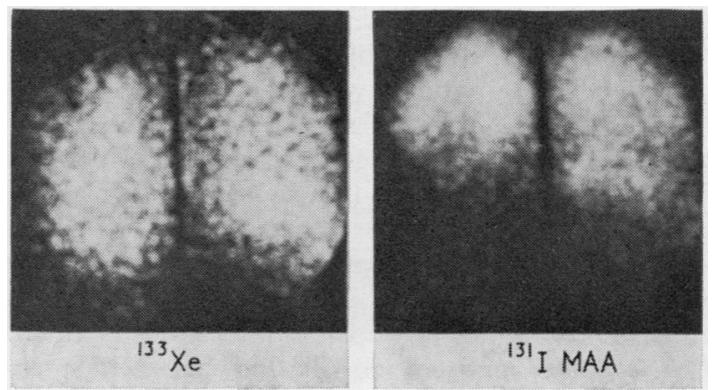

FIG. 3. Ventilation and perfusion scans (antero-posterior projection) in a patient with severe airways obstruction. Marked defects in perfusion are present in the lower lobes, while ventilation is less markedly impaired. The arterial $\mathrm{PO}_{2}$ was $50 \mathrm{~mm}$. $\mathrm{Hg}$ and $\mathrm{PCO}_{2}$ was $53 \mathrm{~mm}$. $\mathrm{Hg}$.
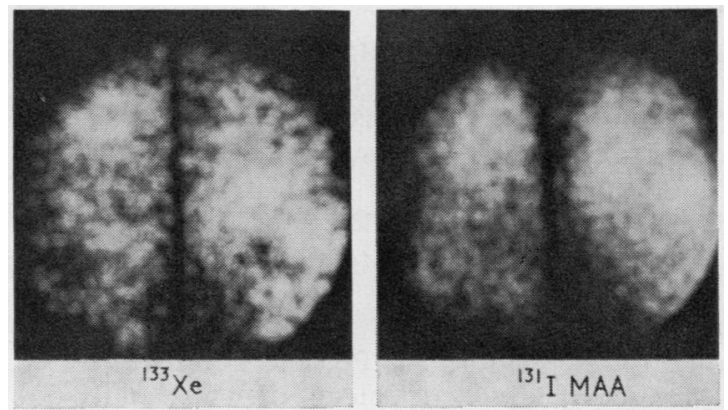

FIG. 4. Ventilation and perfusion scans (antero-posterior projection) in a patient with severe airways obstruction. Both ventilation and perfusion are abnormal, though ventilation defects are more marked. Arterial $\mathrm{PO}_{2}$ was $55 \mathrm{~mm}$. $\mathrm{Hg}$ and $\mathrm{PCO}_{2}$ was $52 \mathrm{~mm}$. $\mathrm{Hg}$.

flow is concentrated in the relatively hypoventilated upper lobes. The arterial $\mathrm{Po}_{2}$ in this case was 50 and $\mathrm{PCO}_{2}$ was 53 , indicating moderate hypoventilation. Another patient with hypoventilation is presented in Figure 4. There is a disparity between ventilation, which is severely impaired in a patchy pattern, and the perfusion, which is also abnormal, but does not visually correspond as well with the ventilation scan as do the examples in Figures 1 and 2.

\section{DISCUSSION}

Evaluation of spirometric and arterial blood gas data for the three groups indicates that, although there is no statistically significant difference between the groups, there are some differences which have clinical importance. Group I patients had the least abnormal values of both spirometric 
and blood gas parameters. Patients in group II had more expiratory obstruction, and group III contained more patients with hypercapnia. Groups II and III had incomplete studies because they were less able to tolerate exercise, and sometimes we thought it would be unnecessary or unwise to give them $5 \% \mathrm{CO}_{2}$ to breathe.

No strong correlation between spirometric studies and blood gas determinations was found consistently in all groups. Palmer and Diament (1968) have reported correlation between spirometric parameters and arterial blood gases in studies where correlation coefficients of 0.3 to 0.5 were found. These were considered valid because of $P$ values showing a high degree of significance. However, such correlation coefficients, while significantly different from zero, are weakly predictive. The practical question we wished to answer was how confidently could one predict arterial blood gas values from spirometric data. For a correlation coefficient of $0 \cdot 3$, for example, only $\left(0 \cdot 3^{2}\right)=$ 0.09 of the total variance is removed when the dispersion of data is measured from the regression line rather than from the mean (Goldstein, 1964). Even a correlation coefficient of 0.5 , where 0.25 of the total variance is removed, is not strongly predictive.

Palmer and Diament (1969) have developed regression equations for $\mathrm{Po}_{2}$ and $\mathrm{PCO}_{2}$ with $\mathrm{FEV}$, where correlation coefficients of 0.582 and 0.604 were obtained. While these are of physiological interest, their use is limited to evaluation of groups of patients rather than predicting arterial blood gas status in a given patient. The values of $\mathrm{Po}_{2}$ and $\mathrm{PCO}_{2}$ derived could not be used to make therapeutic decisions. Two of our patients from group I, whose data are summarized in Table VI, illustrate this point. It is readily apparent that, while both have similar spirometric values, one patient has nearly normal arterial blood gases, while the other is hypoxaemic and hypercapnic.

Such data indicate that spirometric studies alone do not adequately portray the functional status of the patient with chronic airflow obstruction. Accurate pulmonary functional evaluation requires arterial blood gas analysis in each individual patient, at least at rest. Further information of diagnostic and therapeutic value can be derived from arterial blood studies following exercise, $5 \% \mathrm{CO}_{2}$ and $100 \% \mathrm{O}_{2}$ breathing.

The reasons for the spirometric-blood gas disparity are not difficult to identify. The two types of testing are concerned with different aspects of respiratory function. Spirometric studies reflect primarily the mechanical and structural status of the lung-bellows system. The levels of arterial oxygen and carbon dioxide, on the other hand, are influenced by a variety of factors not related to spirometric data, such as the 'match' between ventilation and perfusion, the status of the respiratory control system, the adequacy of alveolocapillary diffusion and the presence of anatomic right-to-left shunts. Thus, it is not surprising that spirometric measurements cannot 'predict' blood gas derangements.

Abnormalities of regional pulmonary blood flow have been described by scintiphotography in patients with chronic airways obstruction. Several possible reasons for perfusion defects may be cited. Areas of regional hypoxia due to inadequate ventilation frequently are poorly perfused due to reflex vasoconstriction and are seen on the scintiscan as patchy 'cold' areas (Lopez-Majano, Wagner, Twining, Tow, and Chernick, 1966). Cysts or bullae of the lung represent large underventilated areas and often produce perfusion defects (Lopez-Majano, Tow, and Wagner, 1966). They may, in addition, compress surrounding lung parenchyma and cause decreased blood flow to these areas. Pulmonary infections, which occur more commonly in emphysematous patients, may leave residual areas of fibrosis which compromise circulation (Bryant, Cohn, O'Neill, Danielson, and Greenlaw, 1968), and also pulmonary emboli are not infrequent causes of scan defects in the emphysematous patient.

Pulmonary scintiscanning, using the techniques described, provides a gross visual image of regional ventilation and perfusion. The ventilation and perfusion scintiphotos and digital data can be compared to determine whether there is a significant disparity between the patterns of air distribution and blood flow. Further refinements of the techniques are now available which permit

T A B LE V I

SPIROMETRIC AND RESTING ARTERIAL BLOOD GAS DATA IN TWO PATIENTS

\begin{tabular}{|c|c|c|c|c|c|c|c|c|c|c|}
\hline Patient & Age & Sex & $\begin{array}{c}\text { VC } \\
\text { (litres) }\end{array}$ & $\underset{(\%)}{R \text { RV }}$ & $\underset{(\%)}{\text { MVV }}$ & $\underset{(\%)}{\mathrm{FEV}_{1 \cdot 0}}$ & $\underset{\text { sec }}{\text { MMFR/ }}$ & $\mathrm{PO}_{2}$ & $p \mathbf{H}$ & $\mathrm{PCO}_{2}$ \\
\hline $\begin{array}{l}\text { E.J.J. } \\
\text { W.P. }\end{array}$ & $\begin{array}{l}53 \\
65\end{array}$ & $\begin{array}{l}\mathbf{M} \\
\mathbf{M}\end{array}$ & $\begin{array}{l}1.56 \\
2.78\end{array}$ & $\begin{array}{l}65 \cdot 7 \\
51 \cdot 3\end{array}$ & $\begin{array}{l}28 \cdot 6 \\
28 \cdot 2\end{array}$ & $\begin{array}{l}36 \cdot 3 \\
43 \cdot 3\end{array}$ & $\begin{array}{l}0.19 \\
0.47\end{array}$ & $\begin{array}{l}79 \\
62\end{array}$ & $\begin{array}{l}7 \cdot 45 \\
7 \cdot 40\end{array}$ & $\begin{array}{l}35 \\
56\end{array}$ \\
\hline
\end{tabular}


more accurate definition of regional ventilation/ perfusion ratios, providing both visual and digital data for small areas of lung.

Our data document the low degree of correlation between spirometric and arterial blood flow gas values. It has been shown that the degree of ventilation/perfusion inequality in the emphysematous patient is an important factor in determining the presence or absence of arterial blood gas abnormalities (Smart et al., 1961 ; Gaida, 1965 ; Lopez-Majano et al., 1966 ; Arborelius, 1969). Our studies emphasize again the central role of the ventilation/perfusion relationship. When ventilation and perfusion are well matched, arterial blood gases remain normal in spite of severe spirometric abnormalities. If, however, there is a significant disparity between ventilation and perfusion in large areas of lung, arterial unsaturation and/or hypercapnia ensue.

No single parameter of pulmonary function is sufficient to provide adequate evaluation of the patient with chronic airflow obstruction. A study of spirometric measurements and arterial blood gas analysis shows that combining several available diagnostic techniques permits a more rational approach to diagnosis and therapy in a given patient as well as a better insight into airways obstruction.

The writers thank Dr. John Evans for statistical assistance in the preparation of this manuscript.

This study was supported in part by grants from the American Medical Association Education and Research Foundation and the John A. Hartford Foundation.

\section{REFERENCES}

Anger, A. O. (1963). Gamma-ray and positron scintillation camera. Nucleonics, 21, October (no. 10), p. 56.

Arborelius, M., Jr. (1969). Influence of unilateral hypoventilation on distribution of pulmonary blood flow in man. J. appl. Physiol., 26, 101 .
Baldwin, E. deF., Cournand, A., and Richards, D. W. (1949). Pulmonary insufficiency. III. A study of 122 cases of chronic pulmonary emphysema. Medicine (Baltimo)re, 28, 201.

Boushy, S. F., and Coates, E. O. (1964). The prognostic value of pulmonary function tests in emphysema: with special reference to arterial blood studies. Amer. Rev. resp. Dis., 90, 553.

Bryant, L. R., Cohn, J. E., O'Neill, R. P., Danielson, G. K., and Greenlaw, R. H. (1968). Pulmonary blood flow distribution in chronic obstructive airway disease: Lung scintiscanning and pulmonary arteriography. Amer. Rev. resp. Dis., 97, 832.

Burrows, B., and Earle, R. H. (1969). Course and prognosis of chronic obstructive lung disease: A prospective study of 200 patients. New Engl. J. Med., 280, 397.

Dore, E. K. Poe, N. D. Ellestad, M. H., and Taplin, G. V. (1968) Lung perfusion and inhalation scanning in pulmonary emphysema. Amer. J. Roentgenol., 104, 770.

Gaida, A. (1965). Discordanze fra reperti spirometrici ed emogasometrici in una omogenea casistica di enfisema polmonare conclamato. Minerva med., 56, parte sci, p. 2353.

Goldstein, A. (1964). Biostatics, p. 145. Macmillan, New York.

Lopez-Majano, V., Wagner, H. N., Jr., Twining, R. H., Tow, D. E., and Chernick, V. (1966). Effect of regional hypoxia on the distribution of pulmonary blood flow in man. Circulat. Res., 18, 550.

- Tow, D. E., and Wagner, H. N., Jr. (1966). Regional distribution of pulmonary arterial blood flow in emphysema. J. Amer. med. Ass., 197, 81 .

Moser, K. M., and Miale, A., Jr. (1968). Interpretive pitfalls in lung photoscanning. Amer. J. Med., 44, 366.

Newhouse, M. T., Wright, F. J., Ingham, G. K., Archer, N. P., Hughes, L. B., and Hopkins, O. L. (1968). Use of scintillation camera and 135-xenon for study of topographic pulmonary function. Resp. Physiol., 4, 141.

Palmer, K. N. V., and Diament, M. L. (1968). Relative contributions of obstructive and restrictive ventilatory impairment in the production of hypoxaemia and hypercapnia in chronic bronchitis. Lancet, 1, 1233.

- (1969). Dynamic and static lung volumes, blood-gas tensions, and transfer factor in chronic obstructive bronchitis. Lancet, $1,1073$.

Segall, J. J., and Butterworth, B. A. (1966). Ventilatory capacity in chronic bronchitis in relation to carbon dioxide tension. Scand. J. resp. Dis., 47, 215.

Shibel, E. M., Landis, G. A., and Moser, K. M. (1969). Inhalation lung scanning evaluation-radioaerosol versus radioxenon techniques. Dis. Chest, 56, 284.

Sinclair, J. D. (1955). The progress of pulmonary deficiency in emphysema. Brit. J. Tuberc., 49, 157.

Smart, J., Naimi, S., and Capel, L. H. (1961). The relationship between effort intolerance, spirometry and blood gas analysis in patients with chronic obstructive airway disease. Brit. J. Dis. Chest, 55,6 .

Sukumalchantra, Y., and Williams, M. H. (1965). Serial studies of pulmonary function in patients with chronic obstructive pulmonary disease. Amer. J. Med., 39, 941.

Tisi, G. M., Landis, G. A., Miale, A., Jr., and Moser, K. M. (1968). Quantitation of regional pulmonary blood flow: validity and potential sources of error. Amer. Rev. resp. Dis., 97, 843.

Wagner, H. N., Jr., Sabiston, D. C., Jr., Iio, M., McAfee, J. G., Meyer, J. K., and Langan, J. K. (1964). Regional pulmonary blood flow in man by radio-isotope scanning. J. Amer. med. Ass., 187, 601 